\title{
COVID-19 and Standardized Vaccines Development: A Brief Review
}

\author{
Nisha Kaushik ${ }^{1}$, Arti R. Thakkar ${ }^{1}$, K. Bangarurajan ${ }^{2}$ \\ ${ }^{1}$ Amity Institute of Pharmacy, Amity Universty, Uttar Pradesh, Noida, India \\ ${ }^{2}$ Central Drugs Standard Control Organisation, HQ, Directorate generl of Health Services, \\ Ministry of Helath Family Welfare, Govt. of India, FDA Bhawan, New Delhi, India
}

Corresponding Author Nisha Kaushik

Amity Institute of Pharmacy, Amity Universty, Uttar Pradesh, Noida, India

Email: nkaushik09@gmail.com

D.O.I-10.51201/JUSST/21/05148

http://doi.org/10.51201/JUSST/21/05148 


\section{ABSTRACT}

The severe acute respiratory syndrome coronavirus disease (COVID-19) pandemic brings a global emergency affecting all civilizations.After the initial spread from Wuhan City atypical form of pneumonia to other areas of the world led the world health organization to look after it as a pandemic situation. The clinical coronavirus now spread all over the globe and brutally affected almost all countries including community transmission. The current capital of coronavirus cases in the US, trailed by India and Brazil, respectively. The most common symptoms were mild to moderate respiratory discomfort. Lung was the main targeting organ for COVID-19 infection resulting in severe pneumonia. Furthermore, severe acute respiratory distress syndrome (ARDS), acute cardiac injury, along with pathological features such as RNAaemia with shared groundglass opacities that may be a cause for death in patients. The surface glycoproteins may be responsible for this garnishing of the virus belonging to the Coronaviridae family.Vaccines work to enhance the immune system of the body by training and making it ready to fight a specific pathogenic agent. At present there over 50 COVID-19 vaccine candidates are in trials, some of which are now ready to deliver via emergency use authorization (EUA). The vast majority of viral vaccines currently licensed for humans can be categorized as inactivated or live-attenuated viruses and protein-based subunit vaccines. Hence, we hereby review the significance of certain genotypic vaccines that are currently subjected for development such as non-replicating viral vectors, mRNA vaccine, self-amplifying mRNA vaccine, DNA vaccine, whole-virus inactivated vaccine, and a subunit vaccine. The current review also explores the mode of pathogenesis and invasion of COVID-19 virus to host cell that would be well-comprised data for future studies in the concerned area of interest.

Keywords: COVID-19; ARDS; DNA vaccine; mRNA vaccine; severe acute respiratory syndrome coronavirus 2 


\section{INTRODUCTION}

Coronaviruses are known to cause illnesses with the common cold to more severe diseases in different animals. Patients suffering from pneumonia with unknown etiology were drastically increasing during December 2019, in Wuhan, China (1). Latter these patients were diagnosed with a series of acute atypical respiratory diseases. The rapid spread of this atypical form of pneumonia to other areas of the world led the scientist and world health organization to look after it as a pandemic situation. Soon it was detected as a novel betacoronavirus was responsible (2). The genomic study revealed to name it as "severe acute respiratory syndrome coronavirus-2 (SARS-CoV-2, 2019-nCoV)”. SARS-CoV-2, because of its high transmission rates than other coronaviruses, is reflected as an alarm for a serious threat to the public health sector $(3,4)$. It was detected to be originated via zoonotic transmission from bats, however,the latter investigation brings the role of an unknown intermediate host for amplification to cause human infection (5). This viral disease presently termed COVID-19 (coronavirus disease 2019) was declared as a pandemic by the World Health Organization (WHO), On March 11, 2020.

The clinical coronavirus now spread all over the globe and brutally affected countries like the United States, Germany, France, Spain, Japan, Singapore, South Korea, Iran, and Italy including community transmission. Initially,the apparent infection was observed in patients admitted to the hospital via nosocomial contagion. Pandemic outbreak with a higher mortality rate in patients with the comorbid condition. Most mortality in comorbid cases was related to diabetes, hypertension, and cardiovascular disease. Patients detected with COVID-2019 were suffering from mild upper respiratory tract infections. Clinical observation reflects these patients were asymptomatic with mild to moderate respiratory discomforts, fever, cough, and flu (6-8). Samples collected from respiratory tract samples of patients suffering from COVID-19 were 
diagnosed via molecular techniques likereal-time reverse transcription polymerase chain reaction (RT-PCR).

This pandemic brings a global emergency affecting all civilizations. As a proper treatment was not available and no medicine was clinically tested and approved, to control the current outbreak worldwide lockdown was called to save billions of human lives across the globe. Thus, the world is in desperate need of effective medicine and operational vaccines against COVID-19. Aiming to clarify in this review, we explore an overview of COVID-19 and standardized vaccines development.

\section{TRANSMISSION}

After initial spreading from Wuhan City through a local seafood market (“wet market”) in China, the virus has taken the disastrous transmission all over the globe. A cause of transmission was person-to-person close contact. The source of transmission is heavy droplets inoculation in normal humans via sneezing and coughing by an infected patient. Soon it was identified that humans without any history of wildlife contact were also suffering from the coronavirus infection. With unknown etiology, numerous populations are now susceptible to COVID-19 infection. Clinical experiences with the virus laid down the conclusion that people who are immunocompromised and mostly with hepatic and renal dysfunction were considered to be highly susceptible (9). Furthermore, elderly people are at high risk of getting infected with coronavirus probably due to a pathetic immune system that allows quicker growth of viral infection $(10,11)$.

\section{COVID 19 CASES GLOBALLY}

Globally, by this time, January 17, 2021, there have been 94,963,847 confirmed cases of COVID-19, including 2,050,857 deaths, reported to WHO(12). Ever since the diagnosis of the 
first confirmed case of SARS-CoV-2, more than 216 countries have been affected with an average mortality rate of almost 3.0\%(13).However, the number of deaths reported officially is ambiguous to be factual or not. For a more accurate prediction of death upsurge, this year with COVID-19 could be obtained with a comparative analysis of deaths in recent few years. Over the past few months, coronavirus cases rise in several areas of the globe and huge cases are being reported daily for COVID-19.

\section{SYMPTOMS}

The most common symptoms were mild to moderate respiratory discomfort. Elderly people infected with the COVID-19 virus will with underlying comorbidities such as chronic respiratory disease, cardiovascular disease, cancer, and diabetes are serious threats $(14,15)$.The virus spreads primarily via nasal discharge while coughing and sneezing or droplets of saliva from an infected person.

Laboratory diagnosis of patients infected with COVID-19 displays onset of symptoms from upper respiratory tract samples. The average incubation period of COVID-19 was between 3 and 14 days(12). The virus may persist for 7 to12 days in moderate cases and the severely affected patient's time period may be as long as two weeks (2). The onset of symptoms could be shorter in elderly patients (9).

COVID- 19 patients may become suspect after initial symptoms of dry cough with fever and dyspnea. Depending upon the immunity status of patients it could be categorized as symptomatic, infective, asymptomatic, and carrier.Mild COVID-19 cases with malaise, rhinorrhea, sore throat, diarrhea, vomiting, nausea, hemoptysis with or without abdominal pain, and conjunctivitis also been reported however with no evidence of pneumonia and with stable psychological functions(16). Patients categorized under moderate COVID-19 infection indicate 
respiratory symptoms including dry cough and shortness of breath with fever. While patients with severe illness displayed the sign of dyspnea, as identified by chest radiograph showing infiltrate in the upper lobe of the lung with hypoxemia (17). Furthermore, these patients also reported suffering from anorexia and abdominal pain, and fever along with blood oxygen saturation $<93 \%, \mathrm{PaO} 2 / \mathrm{FiO} 2$ ratio $<300$, and/or lung infiltrates $>50 \%$ of the lung field within 24 to $48 \mathrm{hr}$.

Patients were also found to be identified with less common symptoms like gastrointestinal, anosmia, dysgeusia(5). In such cases, laboratory testing of fecal and urine samples could help to restrain further transmission of the virus $(18,19)$.After 7 days or more of persistent infection, patients with the above three categories may prone to develop critical illness and emerge out with acute respiratory distress syndrome (ARDS)(20). These patients were under the stringent requirement of mechanical ventilation besides metabolic acidosis, multiorgan dysfunction failure, and coagulation dysfunction(21-23).

\section{PATHOPHYSIOLOGY OF COVID-19}

Lung was the main targeting organ for COVID-19 infection resulting in severe pneumonia. Furthermore, severe acute respiratory distress syndrome (ARDS), acute cardiac injury, along with pathological features such as RNAaemia with shared ground-glass opacities that may be a cause for death in patients suffering from COVID-19 (2). Higher leukocyte numbers, abnormal respiratory findings, and increased levels of plasma pro-inflammatory cytokines are the trademarks for patients suffering from COVID-19(24). Laboratory finding directs the COVID-19 patients to leucopenia, hypoalbuminemia, and lymphopenia(2, 25). For patients on mechanical ventilation and/or on intensive care, an upsurge in the neutrophil to lymphocyte ratio (NLR) could be a notable laboratory marker for severe illness (26). 
Significantly high levels of inflammatory markers for instance d-dimer, c-reactive protein, and erythrocyte sedimentation rate were noted. Predictable and elevated plasma concentrations of chemokines and cytokines are present $(2,27)$. This might includes basic FGF2, GCSF, GMCSF, IFN $\gamma$, IL1- $\beta$, IL1RA, IL7, IL8, IL9, IL10, IP10, MCP1, MIP1 $\alpha$, MIP1 $\beta$, PDGFB, TNF $\alpha$, and VEGFA. Infrequently, in some severe cases, disease mortality may be promoted with the release of pro-inflammatory cytokines including GCSF, IL2, IL7, IL10, IP10, MCP1, MIP1 $\alpha$, and TNF $\alpha$ may trigger Cytokine Release Syndrome (CRS) in patients(28, 29).

\section{SARS-COV-2 INVASION INTO HOST CELLS}

Electron microscopic studies revealed the crown-like exterior of this virus, Latter it was named as coronavirus. The surface glycoproteins may be responsible for this garnishing of the virus belonging to the Coronaviridae family. Coronaviruses are large single-stranded RNA viruses of $\sim 30 \mathrm{~kb}$ with positive-sense and infect a wide variety of host species(30). Based on their genomic structure they are classified into four genera; $\alpha, \beta, \gamma$, and $\delta$. Out of these $\alpha$ and $\beta$ genera are identified to cause disease in humans. Coronavirus from $\alpha$ genera for example $\mathrm{HCoV}-$ 229E and HCoV-NL63 may lead to common cold and cough in humans. While Coronavirus from $\beta$ genera such as $\mathrm{HCoV}-\mathrm{OC} 43$ and $\mathrm{HCoV}-\mathrm{HKU} 1$ were recognized for Middle East respiratory syndrome coronavirus (MERS-CoV) and SARS-CoV-2 (31). This enveloped coronavirus RNA genome encodes for numerous open reading frames to design the life cycle of the virus to go through attachment, penetration, biosynthesis, maturation, and release(32). Attachment to host receptors brings endocytosis to track entry into host cells via membrane penetration (fusion). The onset of viral RNA replication inside the nucleus shifts the path to biosynthesis (viral proteins). After maturation new viral particles were released. Chiefly four structural proteins namely Spike (S), membrane (M), envelop (E) and nucleocapsid (N) makes the coronavirus (33). Spike is overextended from the viral surface and contains a transmembrane 
trimetric glycoprotein. It is composed of two functional subunits S1 subunit leads to the host cell receptor binding and the S2 subunit is responsible for the penetration into cellular membranes. The principal organs involved in SARS-CoV infection are the lungs. One of the functional receptors that were exploited in the alveolar space for this virus is Angiotensin-converting enzyme 2 (ACE2) (34). ACE2 is highly expressed over the distal airway on the apical side of lung epithelial cells. Hence, this may be a leading cause for early lung injury in COVID-19 Patients(35, 36). Apart from this, ACE2 expression was high in the heart, ileum, kidney, and bladder. Studies with functional and structural characterization of SARS-CoV-2 revealed that the spike protein undergoes protease cleavage after binding to ACE2 $(37,38)$. The uncommon spike in coronavirus is because of a range of different proteases that can cleave and activate it (39). Cellular surface serine protease TMPRSS2 and cathepsin L are may be responsible for cleavage, which may also facilitate membrane penetration with host cells $(40,41)$. The pathogenicity could also have been related to the unique abundant expression of furin. A proposed as a model consisting of two-step sequential protease cleavage to activate spike protein of SARS-CoV and MERS-CoV. Comprises of priming via the S1/S2 cleavage site and activation via a position adjacent to a fusion peptide within the $\mathrm{S} 2$ subunit, i.e. the $\mathrm{S}^{\prime} 2$ site $(42,43)$. Non-covalent binding of S1 and S2 subunits while the distal S1 subunit pays stabilization of the membrane-anchored S2 subunit at the prefusion state(38). Followed by cleavage at the $\mathrm{S}^{\prime 2}$ site. This could lead to probable activation of the spike for membrane fusion through irreversible, conformational changes. The disease pathogenesis and severity are a result of cytokine storm and virus evasion of cell-mediated $(44,45)$. Apart from ACE2, the viral spikes could also bind to dendritic-cell specific intercellular adhesion molecule-3-grabbing nonintegrin (DC-SIGN) and DC-SIGNrelated protein (DC-SIGNR, L-SIGN). The components for innate immunity were epithelial cells, alveolar macrophages, and dendritic cells (DCs) in the airway (46, 47). Specifically, DC- 
SIGN is highly expressed over alveolar macrophages and dendritic cells (DCs). Where the innate immune cellular responses are on the apical side of the epithelium were shielded with macrophages and DCs reside underneath the epithelium to fight against viruses till adaptive immunity is involved. Furthermore, Virus-Infected apoptotic cells could be phagocytized through DCs and macrophages (44), which leads to antigen presentation to T cells.

More precisely, $\mathrm{T}$ cell responses are initiated by antigen presentation via DCs and macrophages(30).Viral antigens could face $\mathrm{T}$ cells via the passage of draining lymph nodes. Virus-specific antibody formation is initiated via B cell activation, for which CD4+ and CD8+ T cells play a decisive role to eradicate virally infected cells. Downfall of T cells follow-on to the progression of the disease. COVID-19 patients with the severe disease also reported having unusual pathogenic CD4+ $\mathrm{T}$ cells with co-expressing interferon (IFN)- $\gamma$ and granulocytemacrophage colony-stimulating factor (GM-CSF) (48). Though GM-CSF may cause excessive tissue damage, it could augment $\mathrm{T}$ cell function and promote differentiation of innate immune cells $(49,50)$.

\section{VACCINE DEVELOPMENT}

Vaccines work to enhance the immune system of the body by training and making it ready to fight a specific pathogenic agent that may encounter with the body's natural defenses system later. At present there over 50 COVID-19 vaccine candidates are in trials, some of which are now ready to deliver via emergency use authorization (EUA) (51). The vast majority of viral vaccines currently licensed for humans can be categorized as inactivated or live-attenuated viruses and protein-based subunit vaccines such as those with purified proteins. Viral vaccines are more immunogenic, hence poses a low safety scale, while in the latter case, subunit vaccines are safer and show less immunogenicity(52). 


\subsection{Non-replicating viral vectors (NRVV)}

As in the previous section, we had to understand the role of S protein to gain entry into the host cell. The majority of vaccines are adenoviral based on either they are using S protein as subunits or full-length S protein (53-55).Adenoviruses are a double-stranded DNA virus that works by detaining replication (56). Thereby, improving immunogenicity by provoking cytokine and chemokine release, possibly by the upsurge of transgene expression and upregulation of costimulatory molecules(57).

However, pre-existing immunity against multiple adenovirus strains, mark efficacy $(55,58)$. The design of the SARS-CoV-2 vaccine candidate comprises of adenovirus type 5 with reports to develop immunity after intranasal inoculation in animals. Though intramuscular injection was also been studied, it is found to be less effective than intranasal administration. Chimpanzee adenovirus-vectored vaccine was also been used as a candidate by the University of Oxford, in collaboration with AstraZeneca that expresses the full S protein (AZD-1222, previously known as ChAdOx1-nCoV)(55). Long-term immunity development needs the administration of booster dose after 28 days of the first vaccine cycle $(59,60)$.

\section{2mRNA vaccine}

Numerous, messenger RNA vaccines are under development due to their cheaper production cost than protein subunit vaccine and the nucleic acid vaccine is affordable regarding speedy manufacturing (61). In addition to it mRNA vaccine better cellular and humoral immune response possibly due to the open reading frame of the targeted antigen with a 3 ' polyadenylated tail (62). However, stability is a matter of concern in the successful delivery of nucleic acid vaccine candidates as they are prone to degrade faster (63). National Institute of Allergy and Infectious Diseases (NIAID) in collaboration with Moderna developing an mRNA SARS CoV-2 
vaccine that encodes for glycoprotein-derived spike-2 protein antigen (64). It was initially evaluated in nonhuman primates and has successfully induced a robust anti-SARS-CoV-2 neutralizing antibody response and rapid protection against pulmonary injury $(65,66)$. BioNTech and Pfizer have created four RNA-based vaccine candidates explored in early-stage clinical trials, two of which proceeded to further testing. Their vaccines were also embedded in LNP and encode perfusion-stabilized, membrane-anchored SARS-CoV-2 full-length spike(67).

\subsection{Self-amplifying mRNA vaccine}

Plasmids of Trinidad donkey Venezuelan equine encephalitis virus strains (VEEV) were utilized for the design of saRNA vaccines. As these vaccine candidates have RNA sequence for replicon and the Spike protein its length may pose a limitation, Nevertheless, immunological response produces are vibrant than a non-replicating mRNA vaccine. The VEEV structural coding regions are then replaced with pre-fusion Spike protein of SARS-CoV-2, while the selfamplifying coding region of VEEV alphavirus remains conserved. At present, Arcturus/DUKENS, and the University of Washington, Imperial College in London, were working on SARS CoV- 2 vaccine as a nanoparticle formulation self-amplifying RNA constructs (68).

\subsection{DNA vaccine}

DNA vaccine offers numerous benefits in regards to enormous capacity to produce mRNA molecules and improved thermal stability and superior immunologic response. Inovio Pharmaceuticals developed a vaccine on a consensus SARS-CoV-2 spike glycoprotein sequence with an N-terminal IgE leader with higher immunogenicity (69). Additionally, humoral and cellular immune components were recognized in bronchoalveolar lavage fluid. A SARS-CoV-2 DNA-based vaccine candidate (INO-4800) also enhances expression in target cells.

\subsection{Whole-virus inactivatedvaccine}


Vaccines that use inactivated pathogens to induce immunity with lessen sided effects. [66]. However, longer production time may put some limitations in the case of large scale manufacturing and delivery. At present time, promising beta-propiolactone-induced inactivated SARS-CoV-2 vaccine candidates that are transmitted via Vero (African Green Monkey) cell lines are under study in China. The viral particle is then adsorbed onto an adjuvant (aluminum hydroxide) (70).

\subsection{Subunit vaccine}

Unlike, whole-pathogen vaccines, protein subunit vaccine candidatescomprise of recombinant spike protein offering scalability and radical safety. Usually, various cell lines from insects could be used to segregate a recombinant spike protein. It may require multifarious immunizations and display less immunogenicity (52). Moreover, in vivo stability and Immune response could also have been enhanced via nanoparticle-based approaches which could be adsorbed on specific adjuvants to produce finished Vaccine formulation. Similar to RNA-based approaches, peptides are often unstable in vivo.The protein vaccine by Novavax, consists of a nanoparticle designed to capable of binding ACE2 receptors with high affinity.

\section{INDIA REGULATORY SYSTEM : THE SUBJECT EXPERT COMMITTEES (SEC) ROLE}

Import or manufacture for sale of drugs including vaccines are regulated under Drugs and Cosmetics act, 1940 and Drugs \& Cosmetics rules, 1945 and New Drugs and clinical trials rules, 2019. Detailed requirements and guidelines for conduct of nonclinical and clinical studies and approval of new drug which includes vaccine are specified in second schedule of new drugs and clinical trials rules, 2019. As per the rules, products like vaccines, r-DNA derived products, LMO, stem cell derived products, and gene therapeutic products, etc are always considered to be 
new drugs. for such products manufacturers are required to obtain manufacturing permission from CDSCO under the new drugs and clinical trials rules, 2019 before licencing the product under the drugs and cosmetics rules,1945 the manufacturing licence for such product is granted after joint evaluation and inspection by the concerned state licencing authority \&CDSCO.

In general, all vaccines including the vaccines against corona virus infection manufactured / imported into the country are required to comply with the requirements and guidelines specified in the drugs and cosmetics rules, 1945 \& new drugs and clinical trials rules, 2019 and other applicable guidelines published by CDSCO form time to time in case of manufacturer r-DNA derived vaccines the requirements and guidelines prescribed by department of biotechnology are also required to be complied with. However, vaccines unlike chemical drugs are complex heterogeneous class of medical products, and hence specific consideration in respect of development of CMC data, non-clinical data, and clinical data will provide clear understanding of regulatory landscape for their development and approval in a scientific manner. Therefore, these documents have been prepared to provide detailed guidelines and regulatory pathways for CMC, nonclinical and clinical development of vaccines including covid-19 vaccines.

The Central Drugs Standard Control Organization (CDSCO) under the Ministry Of Health, Government of India plays an important role in protecting and improving public health by ensuring the consistency, protection, and effectiveness of New Drugs, cosmetics and medical devices.The Subject Expert Committee (SEC) evaluation helpful in the applications of clinical trials and new drugs and their recommendations reviewed by the Technical Review Committee (TRC).SEC is expected to advise the CDSCO office with thorough assessment of clinical data from Phase I to IV furnished by the applicant and nonclinicaldata including pharmacological and toxicological data $(71,72)$.The SEChandling the applications and COVID-19 related proposal during April and December 2020 represented in Figure 1 and 2. 


\section{REFERENCES: -}

1. Cui J, Li F, Shi Z. Ursprung und Evolution von pathogenen Coronaviren. Nat Rev Microbiol. 2019;17:181-92.

2. Yang $\mathrm{X}, \mathrm{Yu} \mathrm{Y,} \mathrm{Xu} \mathrm{J,} \mathrm{Shu} \mathrm{H,} \mathrm{Liu} \mathrm{H,} \mathrm{Wu} \mathrm{Y,} \mathrm{et} \mathrm{al.} \mathrm{Clinical} \mathrm{course} \mathrm{and} \mathrm{outcomes} \mathrm{of}$ critically ill patients with SARS-CoV-2 pneumonia in Wuhan, China: a single-centered, retrospective, observational study. The Lancet Respiratory Medicine. 2020;8(5):475-81.

3. Letko M, Marzi A, Munster V. Functional assessment of cell entry and receptor usage for SARS-CoV-2 and other lineage B betacoronaviruses. Nature microbiology. 2020;5(4):562-9.

4. Wang D, Yin Y, Hu C, Liu X, Zhang X, Zhou S, et al. Clinical course and outcome of 107 patients infected with the novel coronavirus, SARS-CoV-2, discharged from two hospitals in Wuhan, China. Critical Care. 2020;24:1-9.

5. Zhou P, Yang X-L, Wang X-G, Hu B, Zhang L, Zhang W, et al. A pneumonia outbreak associated with a new coronavirus of probable bat origin. nature. 2020;579(7798):270-3.

6. Pan X, Chen D, Xia Y, Wu X, Li T, Ou X, et al. Asymptomatic cases in a family cluster with SARS-CoV-2 infection. The Lancet Infectious Diseases. 2020;20(4):410-1.

7. Lai C-C, Shih T-P, Ko W-C, Tang H-J, Hsueh P-R. Severe acute respiratory syndrome coronavirus 2 (SARS-CoV-2) and coronavirus disease-2019 (COVID-19): The epidemic and the challenges. International journal of antimicrobial agents. 2020;55(3):105924.

8. Singhal T. A review of coronavirus disease-2019 (COVID-19). The indian journal of pediatrics. 2020;87(4):281-6.

9. Wang W, Tang J, Wei F. Updated understanding of the outbreak of 2019 novel coronavirus (2019-nCoV) in Wuhan, China. Journal of medical virology. 2020;92(4):441-7.

10. Li Q, Guan X, Wu P, Wang X, Zhou L, Tong Y, et al. Early transmission dynamics in Wuhan, China, of novel coronavirus-infected pneumonia. New England journal of medicine. 2020.

11. Tran K, Cimon K, Severn M. Pessoa-Silva CL, Conly J. Aerosol generating procedures and the risk of transmission of acute respiratory infections to healthcare workers: A systematic review. PLoS One. 2012;7:e35797.

12. Organization WH, Organization WH. Report of the WHO-China joint mission on coronavirus disease 2019 (COVID-19). Geneva; 2020.

13. Rehman MFu, Fariha C, Anwar A, Shahzad N, Ahmad M, Mukhtar S, et al. Novel coronavirus disease (COVID-19) pandemic: A recent mini review. Computational and Structural Biotechnology Journal. 2021;19:612-23.

14. Feijoo AM, Maseda E, Bartolomé RA, Aguilar G, de Castro RG, Gómez-Herreras J, et al. Practical recommendations for the perioperative management of the patient with suspection or serious infection by coronavirus SARS-CoV. Revista Española de Anestesiología y Reanimación (English Edition). 2020;67(5):253-60.

15. Singh A, Shaikh A, Singh R, Singh AK. COVID-19: From bench to bed side. Diabetes \& Metabolic Syndrome: Clinical Research \& Reviews. 2020;14(4):277-81.

16. ur Rehman MF, Fariha C, Anwar A, Shahzad N, Ahmad M, Mukhtar S, et al. Novel coronavirus disease (COVID-19) pandemic: A recent mini review. Computational and structural biotechnology journal. 2020.

17. Phan LT, Nguyen TV, Luong QC, Nguyen TV, Nguyen HT, Le HQ, et al. Importation and human-to-human transmission of a novel coronavirus in Vietnam. New England Journal of Medicine. 2020;382(9):872-4.

18. Assiri A, Al-Tawfiq JA, Al-Rabeeah AA, Al-Rabiah FA, Al-Hajjar S, Al-Barrak A, et al. Epidemiological, demographic, and clinical characteristics of 47 cases of Middle East respiratory 
syndrome coronavirus disease from Saudi Arabia: a descriptive study. The Lancet infectious diseases. 2013;13(9):752-61.

19. Lee N, Hui D, Wu A, Chan P, Cameron P, Joynt GM, et al. A major outbreak of severe acute respiratory syndrome in Hong Kong. New England Journal of Medicine. 2003;348(20):1986-94.

20. Odor PM, Neun M, Bampoe S, Clark S, Heaton D, Hoogenboom EM, et al. Anaesthesia and COVID-19: infection control. British journal of anaesthesia. 2020.

21. Bauch CT, Lloyd-Smith JO, Coffee MP, Galvani AP. Dynamically modeling SARS and other newly emerging respiratory illnesses: past, present, and future. Epidemiology. 2005:791801.

22. Wang Y, Wang Y, Chen Y, Qin Q. Unique epidemiological and clinical features of the emerging 2019 novel coronavirus pneumonia (COVID-19) implicate special control measures. Journal of medical virology. 2020;92(6):568-76.

23. Lai C-C, Liu YH, Wang C-Y, Wang Y-H, Hsueh S-C, Yen M-Y, et al. Asymptomatic carrier state, acute respiratory disease, and pneumonia due to severe acute respiratory syndrome coronavirus 2 (SARS-CoV-2): Facts and myths. Journal of Microbiology, Immunology and Infection. 2020;53(3):404-12.

24. Song F, Shi N, Shan F, Zhang Z, Shen J, Lu H, et al. Emerging 2019 novel coronavirus (2019-nCoV) pneumonia. Radiology. 2020;295(1):210-7.

25. Chen G, Wu D, Guo W, Cao Y, Huang D, Wang H, et al. Clinical and immunological features of severe and moderate coronavirus disease 2019. The Journal of clinical investigation. 2020;130(5):2620-9.

26. Kong M, Zhang H, Cao X, Mao X, Lu Z. Higher level of neutrophil-to-lymphocyte is associated with severe COVID-19. Epidemiology \& Infection. 2020;148.

27. Cancio M, Ciccocioppo R, Rocco P, Levine B, Bronte V, Bollard CM, et al. Emerging trends in COVID-19 treatment: learning from inflammatory conditions associated with cellular therapies. Cytotherapy. 2020.

28. Ruan Q, Yang K, Wang W, Jiang L, Song J. Clinical predictors of mortality due to COVID-19 based on an analysis of data of 150 patients from Wuhan, China. Intensive care medicine. 2020;46(5):846-8.

29. Yuki K, Fujiogi M, Koutsogiannaki S. COVID-19 pathophysiology: A review. Clinical immunology. 2020:108427.

30. Channappanavar R, Zhao J, Perlman S. T cell-mediated immune response to respiratory coronaviruses. Immunologic research. 2014;59(1):118-28.

31. Chen Y, Liu Q, Guo D. Emerging coronaviruses: genome structure, replication, and pathogenesis. Journal of medical virology. 2020;92(4):418-23.

32. Abduljalil JM, Abduljalil BM. Epidemiology, genome, and clinical features of the pandemic SARS-CoV-2: a recent view. New microbes and new infections. 2020;35:100672.

33. Bosch BJ, Van der Zee R, De Haan CA, Rottier PJ. The coronavirus spike protein is a class I virus fusion protein: structural and functional characterization of the fusion core complex. Journal of virology. 2003;77(16):8801-11.

34. Li W, Moore MJ, Vasilieva N, Sui J, Wong SK, Berne MA, et al. Angiotensin-converting enzyme 2 is a functional receptor for the SARS coronavirus. Nature. 2003;426(6965):450-4.

35. Hamming I, Timens W, Bulthuis M, Lely A, Navis Gv, van Goor H. Tissue distribution of ACE2 protein, the functional receptor for SARS coronavirus. A first step in understanding SARS pathogenesis. The Journal of Pathology: A Journal of the Pathological Society of Great Britain and Ireland. 2004;203(2):631-7. 
36. Jia HP, Look DC, Shi L, Hickey M, Pewe L, Netland J, et al. ACE2 receptor expression and severe acute respiratory syndrome coronavirus infection depend on differentiation of human airway epithelia. Journal of virology. 2005;79(23):14614-21.

37. Chen Y, Guo Y, Pan Y, Zhao ZJ. Structure analysis of the receptor binding of 2019nCoV. Biochemical and biophysical research communications. 2020;525(1):135-40.

38. Walls AC, Park Y-J, Tortorici MA, Wall A, McGuire AT, Veesler D. Structure, function, and antigenicity of the SARS-CoV-2 spike glycoprotein. Cell. 2020;181(2):281-92. e6.

39. Belouzard S, Millet JK, Licitra BN, Whittaker GR. Mechanisms of coronavirus cell entry mediated by the viral spike protein. Viruses. 2012;4(6):1011-33.

40. Ou X, Liu Y, Lei X, Li P, Mi D, Ren L, et al. Characterization of spike glycoprotein of SARS-CoV-2 on virus entry and its immune cross-reactivity with SARS-CoV. Nature communications. 2020;11(1):1-12.

41. Hoffmann M, Kleine-Weber H, Schroeder S, Krüger N, Herrler T, Erichsen S, et al. SARS-CoV-2 cell entry depends on ACE2 and TMPRSS2 and is blocked by a clinically proven protease inhibitor. cell. 2020;181(2):271-80. e8.

42. Belouzard S, Chu VC, Whittaker GR. Activation of the SARS coronavirus spike protein via sequential proteolytic cleavage at two distinct sites. Proceedings of the National Academy of Sciences. 2009;106(14):5871-6.

43. Millet JK, Whittaker GR. Host cell entry of Middle East respiratory syndrome coronavirus after two-step, furin-mediated activation of the spike protein. Proceedings of the National Academy of Sciences. 2014;111(42):15214-9.

44. Fujimoto I, Pan J, Takizawa T, Nakanishi Y. Virus clearance through apoptosisdependent phagocytosis of influenza A virus-infected cells by macrophages. Journal of virology. 2000;74(7):3399-403.

45. Rothan HA, Byrareddy SN. The epidemiology and pathogenesis of coronavirus disease (COVID-19) outbreak. Journal of autoimmunity. 2020;109:102433.

46. Yoshikawa T, Hill T, Li K, Peters CJ, Tseng C-TK. Severe acute respiratory syndrome (SARS) coronavirus-induced lung epithelial cytokines exacerbate SARS pathogenesis by modulating intrinsic functions of monocyte-derived macrophages and dendritic cells. Journal of virology. 2009;83(7):3039-48.

47. Hamid S, Mir MY, Rohela GK. Noval coronavirus disease (COVID-19): A pandemic (Epidemiology, Pathogenesis and potential therapeutics). New microbes and new infections. 2020:100679.

48. Zhou Y, Fu B, Zheng X, Wang D, Zhao C, Qi Y, et al. Pathogenic T-cells and inflammatory monocytes incite inflammatory storms in severe COVID-19 patients. National Science Review. 2020;7(6):998-1002.

49. Croxford AL, Lanzinger M, Hartmann FJ, Schreiner B, Mair F, Pelczar P, et al. The cytokine GM-CSF drives the inflammatory signature of CCR2+ monocytes and licenses autoimmunity. Immunity. 2015;43(3):502-14.

50. $\mathrm{Xu} \mathrm{Z,} \mathrm{Shi} \mathrm{L,} \mathrm{Wang} \mathrm{Y,} \mathrm{Zhang} \mathrm{J,} \mathrm{Huang} \mathrm{L,} \mathrm{Zhang} \mathrm{C,} \mathrm{et} \mathrm{al.} \mathrm{Pathological} \mathrm{findings} \mathrm{of}$ COVID-19 associated with acute respiratory distress syndrome. The Lancet respiratory medicine. 2020;8(4):420-2.

51. Chung JY, Thone MN, Kwon YJ. COVID-19 vaccines: The status and perspectives in delivery points of view. Advanced drug delivery reviews. 2020.

52. Brisse M, Vrba SM, Kirk N, Liang Y, Ly H. Emerging concepts and technologies in vaccine development. Frontiers in immunology. 2020;11:2578.

53. Mercado NB, Zahn R, Wegmann F, Loos C, Chandrashekar A, Yu J, et al. Single-shot Ad26 vaccine protects against SARS-CoV-2 in rhesus macaques. Nature. 2020;586(7830):583-8. 
54. Logunov DY, Dolzhikova IV, Zubkova OV, Tukhvatullin AI, Shcheblyakov DV, Dzharullaeva AS, et al. Safety and immunogenicity of an rAd26 and rAd5 vector-based heterologous prime-boost COVID-19 vaccine in two formulations: two open, non-randomised phase 1/2 studies from Russia. The Lancet. 2020;396(10255):887-97.

55. Zhu F-C, Guan X-H, Li Y-H, Huang J-Y, Jiang T, Hou L-H, et al. Immunogenicity and safety of a recombinant adenovirus type-5-vectored COVID-19 vaccine in healthy adults aged 18 years or older: a randomised, double-blind, placebo-controlled, phase 2 trial. The Lancet. 2020;396(10249):479-88.

56. Benihoud K, Yeh P, Perricaudet M. Adenovirus vectors for gene delivery. Current opinion in biotechnology. 1999;10(5):440-7.

57. Rea D, Schagen FH, Hoeben RC, Mehtali M, Havenga MJ, Toes RE, et al. Adenoviruses activate human dendritic cells without polarization toward a T-helper type 1-inducing subset. Journal of Virology. 1999;73(12):10245-53.

58. Zhu F-C, Li Y-H, Guan X-H, Hou L-H, Wang W-J, Li J-X, et al. Safety, tolerability, and immunogenicity of a recombinant adenovirus type-5 vectored COVID-19 vaccine: a doseescalation, open-label, non-randomised, first-in-human trial. The Lancet. 2020;395(10240):184554 .

59. Folegatti PM, Ewer KJ, Aley PK, Angus B, Becker S, Belij-Rammerstorfer S, et al. Safety and immunogenicity of the ChAdOx1 nCoV-19 vaccine against SARS-CoV-2: a preliminary report of a phase 1/2, single-blind, randomised controlled trial. The Lancet. 2020;396(10249):467-78.

60. van Doremalen N, Lambe T, Spencer A, Belij-Rammerstorfer S, Purushotham JN, Port JR, et al. ChAdOx1 nCoV-19 vaccine prevents SARS-CoV-2 pneumonia in rhesus macaques. Nature. 2020;586(7830):578-82.

61. Graham BS, Mascola JR, Fauci AS. Novel vaccine technologies: essential components of an adequate response to emerging viral diseases. Jama. 2018;319(14):1431-2.

62. Schlake T, Thess A, Fotin-Mleczek M, Kallen K-J. Developing mRNA-vaccine technologies. RNA biology. 2012;9(11):1319-30.

63. Bashirullah A, Cooperstock RL, Lipshitz HD. Spatial and temporal control of RNA stability. Proceedings of the National Academy of Sciences. 2001;98(13):7025-8.

64. Jackson LA, Anderson EJ, Rouphael NG, Roberts PC, Makhene M, Coler RN, et al. An mRNA vaccine against SARS-CoV-2 - preliminary report. New England Journal of Medicine. 2020.

65. Corbett KS, Edwards DK, Leist SR, Abiona OM, Boyoglu-Barnum S, Gillespie RA, et al. SARS-CoV-2 mRNA vaccine design enabled by prototype pathogen preparedness. Nature. 2020;586(7830):567-71.

66. Corbett KS, Flynn B, Foulds KE, Francica JR, Boyoglu-Barnum S, Werner AP, et al. Evaluation of the mRNA-1273 vaccine against SARS-CoV-2 in nonhuman primates. New England Journal of Medicine. 2020;383(16):1544-55.

67. Amanat F, Krammer F. SARS-CoV-2 vaccines: status report. Immunity. 2020;52(4):5839.

68. Erasmus JH, Khandhar AP, Walls AC, Hemann EA, O’Connor MA, Murapa P, et al. Single-dose replicating RNA vaccine induces neutralizing antibodies against SARS-CoV-2 in nonhuman primates. bioRxiv. 2020.

69. Smith TR, Patel A, Ramos S, Elwood D, Zhu X, Yan J, et al. Immunogenicity of a DNA vaccine candidate for COVID-19. Nature communications. 2020;11(1):1-13. 
70. Xia S, Duan K, Zhang Y, Zhao D, Zhang H, Xie Z, et al. Effect of an inactivated vaccine against SARS-CoV-2 on safety and immunogenicity outcomes: interim analysis of 2 randomized clinical trials. Jama. 2020;324(10):951-60.

71. Regulatory_guidelines_for_development_of_Vaccine_20.9.20.pdf (cdsco.gov.in)

72. WHO | WHO finds India’s vaccine regulatory authority compliant with international standards

\section{Figure legends}

Figure 1: Covid-19 related proposal discussed during Apr-Dec 2020

Figure 2:Types of Covid-19 related proposal discussed during Apr-Dec 2020

\section{Total Covid related proposals discussed in SEC during Apr 2020 to Dec 2020=170}

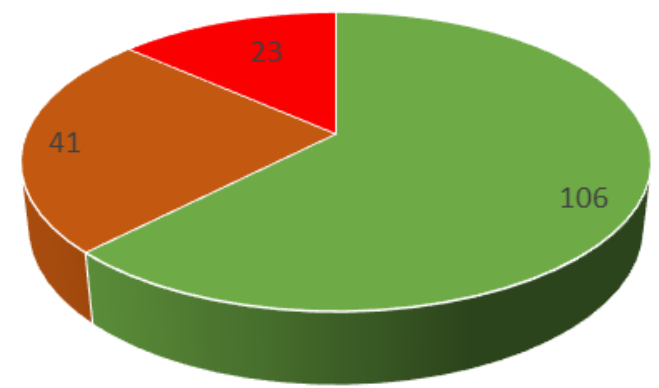

- Proposals approved - Proposals under cosiderations

- Proposal rejected

Figure 1: Covid-19 related proposal during Apr 2020 to Dec 2020 


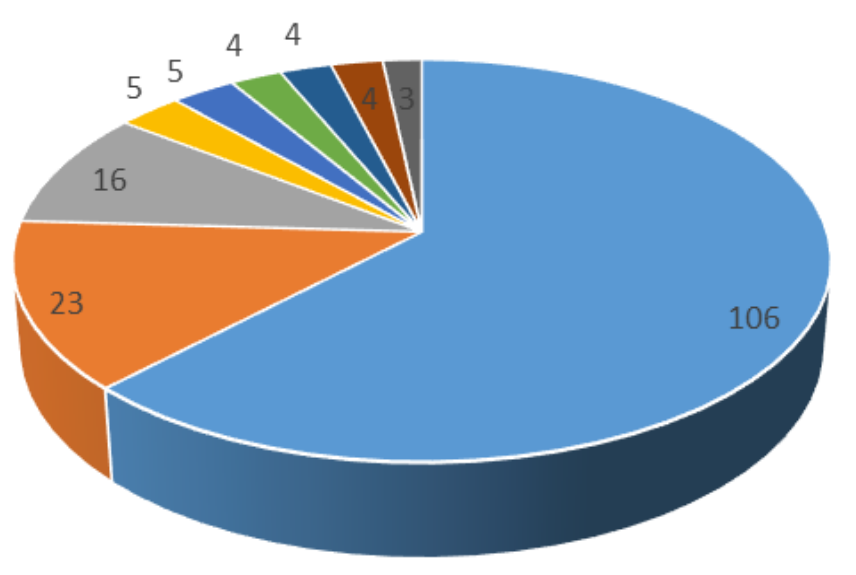

\author{
Field1 \\ - Clinical Trial Proposals (Phase I/II/III] \\ - Manufacturing and Marketing \\ Proposals \\ - Clinical Trial Proposals (Phase \\ IV/PMS) \\ - SND Application Proposals \\ - Academic Trial Proposals \\ - Proposals regarding PK Study
}

Figure 2: Types of Covid-19 related proposal discussed during Apr-Dec 2020 